\title{
DESLOCAMENTOS ESTÉTICOS NA TERRA SANTA - EÇA DE QUEIRÓS E PAULA REGO
}

\author{
AESTHETIC DISPLACEMENTS IN THE HOLLY \\ LAND - EÇA DE QUEIRÓS AND PAULA REGO
}

Isabel Pires de Lima*

\section{RESUMO}

A pintura de Paula Rego tem desenvolvido um intenso e constante diálogo com a literatura. De entre um amplo número de autores, destacam-se os clássicos portugueses de oitocentos, Alexandre Herculano, Camilo Castelo Branco e especialmente Eça de Queirós. Depois de O Crime do Padre Amaro, o romance queirosiano $A$ relíquia mereceu a revisitação da pintora com oito trabalhos nos quais procede a uma prática de ilustração subversora que, não deixando de perseguir a narrativa queirosiana, dela se afasta propondo versões alternativas da história canónica e exercendo por essa via o seu violento e iconoclasta espírito crítico sobre a sociedade contemporânea. Paula Rego pinta em tom paródico o orientalismo queirosiano, ora dele se aproximando, ora dele se afastando em movimentos de deslocação estético-ideológica, num jogo de intermedialidade com Eça de Queirós, que lhe permite confirmar algumas das linhas mestras da sua própria obra.

PALAVRAS-CHAVE: intermedialidade e deslocamento estético; literatura e pintura portuguesas; orientalismo

\section{ABSTRACT}

The work of Paula Rego develops an intense and constant dialogue with the arts, and in particular with literature. Among a large number of authors, it relates to the Portuguese classics of the 1800's, Alexandre Herculano, Camilo Castelo Branco, and particularly Eça de Queirós. After revisiting The crime of Father Amaro, Paula Rego revisited the novel The relic and produced eight subversive paintings that, while relating to the original narra- 
tive, propose alternative versions of the plot, in which the painter exercises her violent and iconoclastic view over contemporary society. This article analyses the three of the aforementioned paintings that refer to excerpts of The relic that take place in the Orient. Paula Rego interprets the orientalism of Queirós by resorting to parody, reinforcing a number of its features while subverting some others, in movements of aesthetic and ideological displacement. Such play of intermediality with Eça de Queirós sets the ground for the confirmation of Paula Rego's body of work.

KEYWORDS: intermediality and aesthetic displacement; Portuguese literature and painting; orientalism

O diálogo de Paula Rego com Eça de Queirós, e aliás com os clássicos portugueses do século XIX, não é de hoje. Data dos finais da década de 90, mais exatamente de 1997, a deslumbrante série de dezasseis pastéis intitulada $O$ crime do Padre Amaro, inspirada no romance homónimo de Eça. Daí para cá vem visitando a pintora outros clássicos oitocentistas, designadamente Camilo Castelo Branco e Alexandre Herculano, cujas obras estão na origem da série de 2001 Maria Moisés e outras histórias, constituída por cinco trabalhos, e de uma outra de 2011/2012, intitulada A Dama Pé-de-Cabra, composta por seis pastéis. Em 2014, exibe em Londres, na galeria Marlborough Fine Art, a exposição O último rei de Portugal e outras histórias, que contempla uma série chamada $A$ relíquia, na qual nos oferece oito pastéis inspirados no romance queirosiano.

O famoso romance, publicado em 1887, conta, em primeira pessoa, a história de Teodorico Raposo, um protagonista com o seu quê de pícaro, cuja vida é dominada pela tia Maria do Patrocínio, beata fanática, sempre rodeada de padres, com quem ele vive, de quem depende economicamente (é bom notar que a tia chama-se exatamente Patrocínio) e cuja fortuna pretende herdar. No sentido de agradar à tia, Teodorico, também chamado de Raposão (alcunha que remete para os estratagemas de raposa matreira de que se socorre), leva uma vida dupla entre a prossecução de uma abnegada prática religiosa imposta pela Titi e a devassidão amorosa e sexual a que se entrega. A tia patrocina-lhe uma viagem à Terra Santa a fim de trazer-lhe uma bela relíquia que lhe garanta a salvação. O cerne do romance é exatamente o relato dessa viagem, que fará na companhia de um erudito alemão, Topsius, durante a qual a duplicidade de Teodorico se confirma na frequência oscilante de lugares sagrados e de casas de prazer mundano; mas essa experiência será ao mesmo tempo uma viagem de formação. Um dos momentos altos do relato respeita a um longo sonho de Teodorico, o qual, regressando à Antiguidade cristã, assiste à pregação, julgamento e crucificação de Jesus, descobrindo um Cristo humano, muito diferente do Cristo da Titi e reescrevendo a história sagrada, nomeadamente ao negar a ressurreição. Teodorico será, porém, vítima de um engano fatal ao trocar dois embrulhos idênticos obtidos no Oriente. Entrega à 
Titi não o embrulho com a relíquia, nada mais do que a própria coroa de espinhos que soubera forjar, mas um embrulho contendo uma camisinha íntima, relíquia dos seus amores devassos com Mary, uma inglesa que encontrara em Alexandria. Os dois embrulhos, note-se, também apontam a referida duplicidade do protagonista, pese embora a sua troca seja também uma espécie de confissão inconsciente das suas culpas. Daqui decorrerá a expulsão de Teodorico da vida da Titi, vendo assim goradas as suas expectativas de herdeiro, e a sua partida para uma nova vida à luz de valores que aprenderá a renovar.

Numa espécie de nota de abertura do relato, Teodorico diz que nele "a Realidade sempre vive, ora embaraçada e tropeçando nas pesadas roupagens da História, ora mais livre e saltando sob a caraça vistosa da Farsa!" (QUEIROZ, 1999, p. 9). Com efeito, este é um romance no qual o olhar realista de Eça permanece acutilante, embora recorra à ficção histórica e a um sarcasmo corrosivo, tudo isso banhado pela sua inigualável ironia.

O título do romance, acrescente-se, é acompanhado da célebre epígrafe: "Sobre a nudez forte da verdade - o manto diáfano da fantasia" (QUEIROZ, 1999, p. 3). Este parece um convite ao pincel de Paula Rego, que, permanecendo sempre preso à captação das contradições do real e do social, não deixa de ser fertilizado e coberto fantasmaticamente pela fantasia. A pintura de Paula Rego convoca habitualmente os fantasmas necessários à encenação das subjetividades, sempre recorrente nos seus quadros, para além das representações mais específicas que pontualmente persegue, e desenvolve um trabalho em torno da imagem que tem o efeito convulsivo que os surrealistas procuravam na perseguição da beleza. Daí decorrerá certamente o facto de a sua obra provocar uma forte comoção em quem a contempla, independentemente de provocar adesão ou repulsa.

Como foi referido, a série $A$ relíquia contempla oito pastéis ${ }^{2}$, intitulados:

\section{Jantarada (Dinner party)}

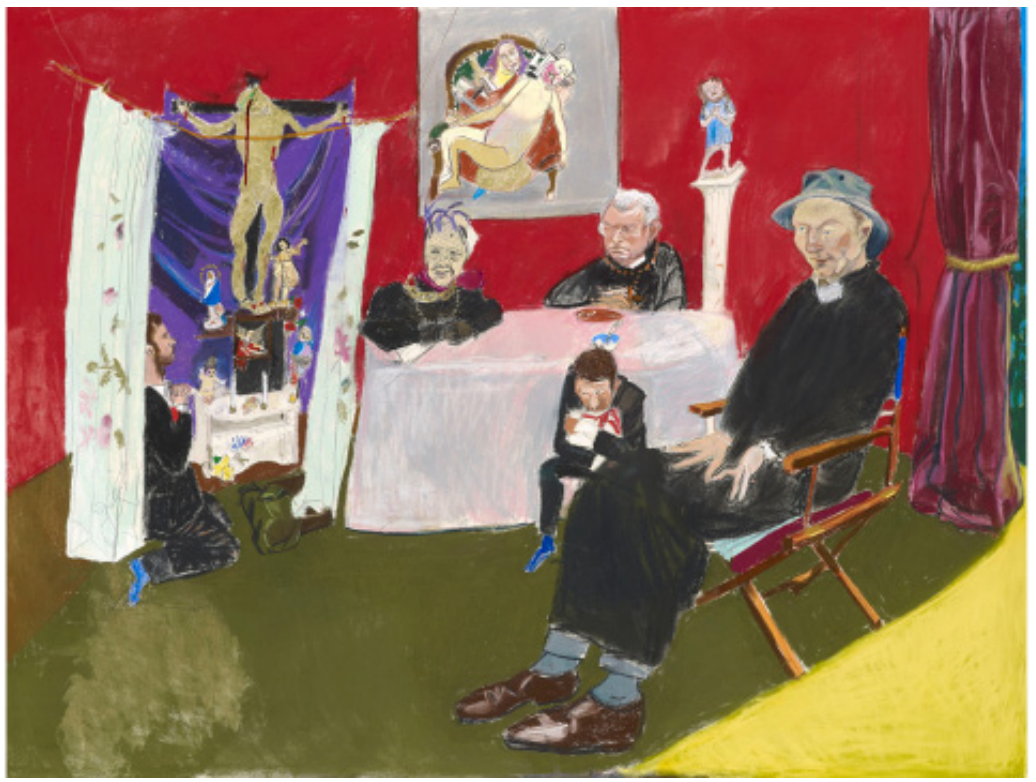


Nossa Senhora das Dores (Our Lady of Sorrow)

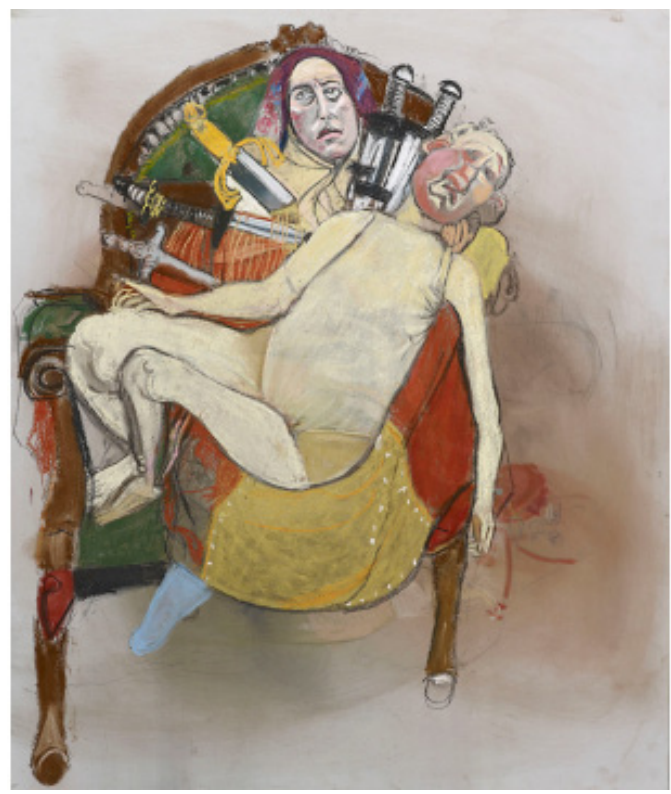

Serenata (Serenade)

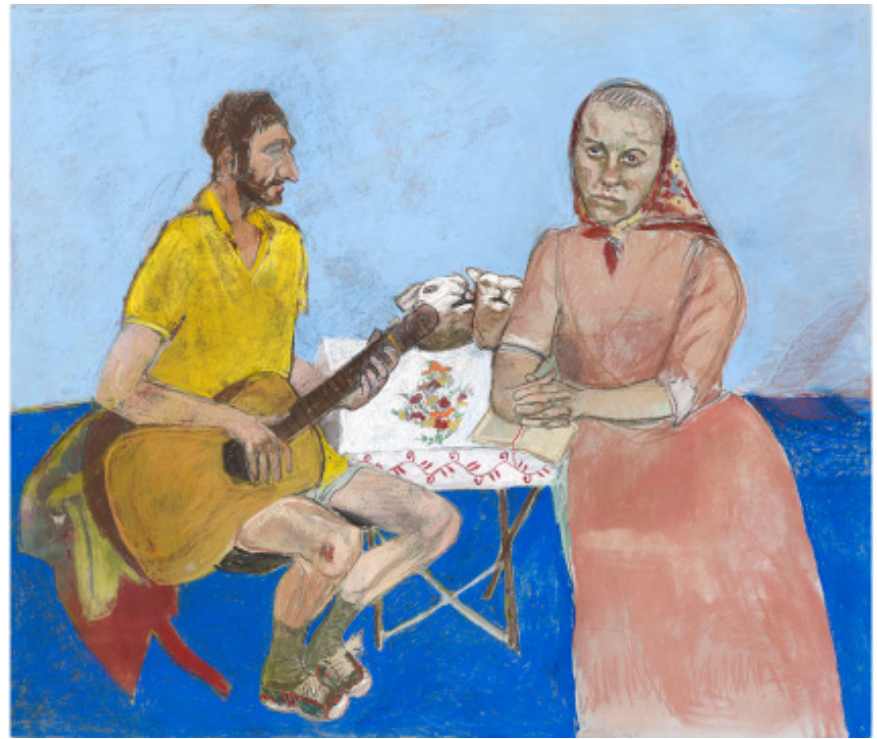

Encontro com Adélia (Meeting Adélia)

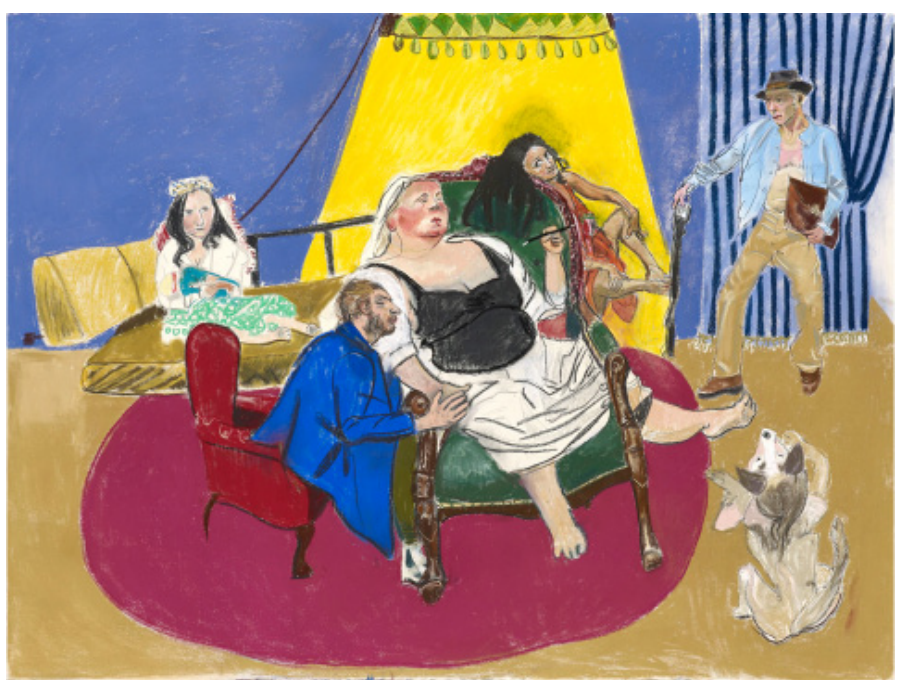


Mary faz luvas (Mary makes gloves)

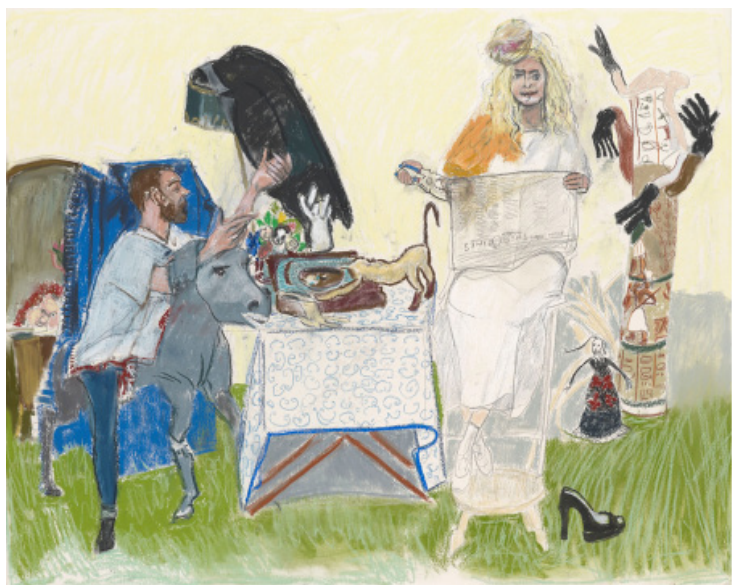

Sonho (Dream)

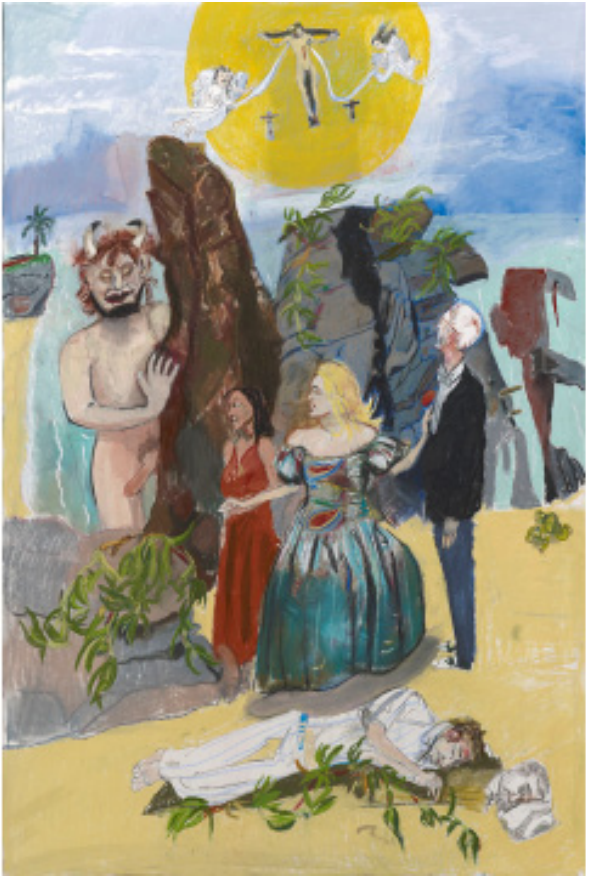

A Terra Santa (The Holly Land)

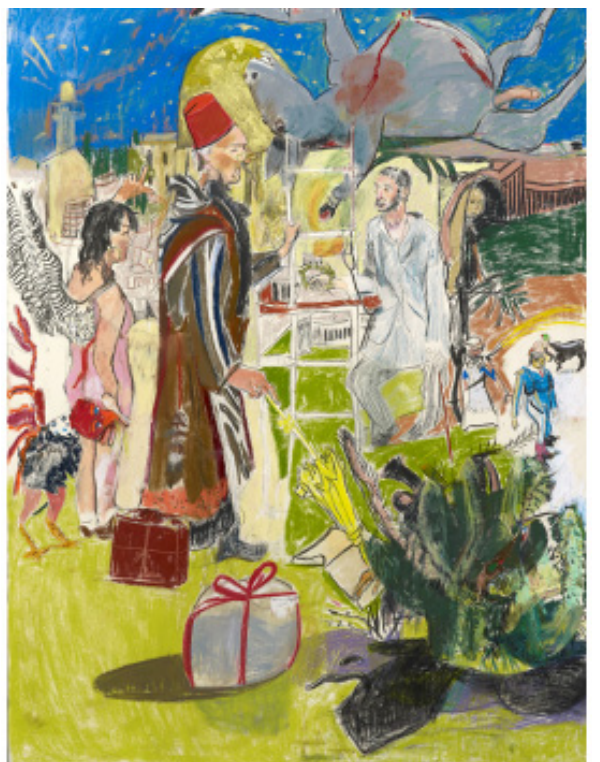




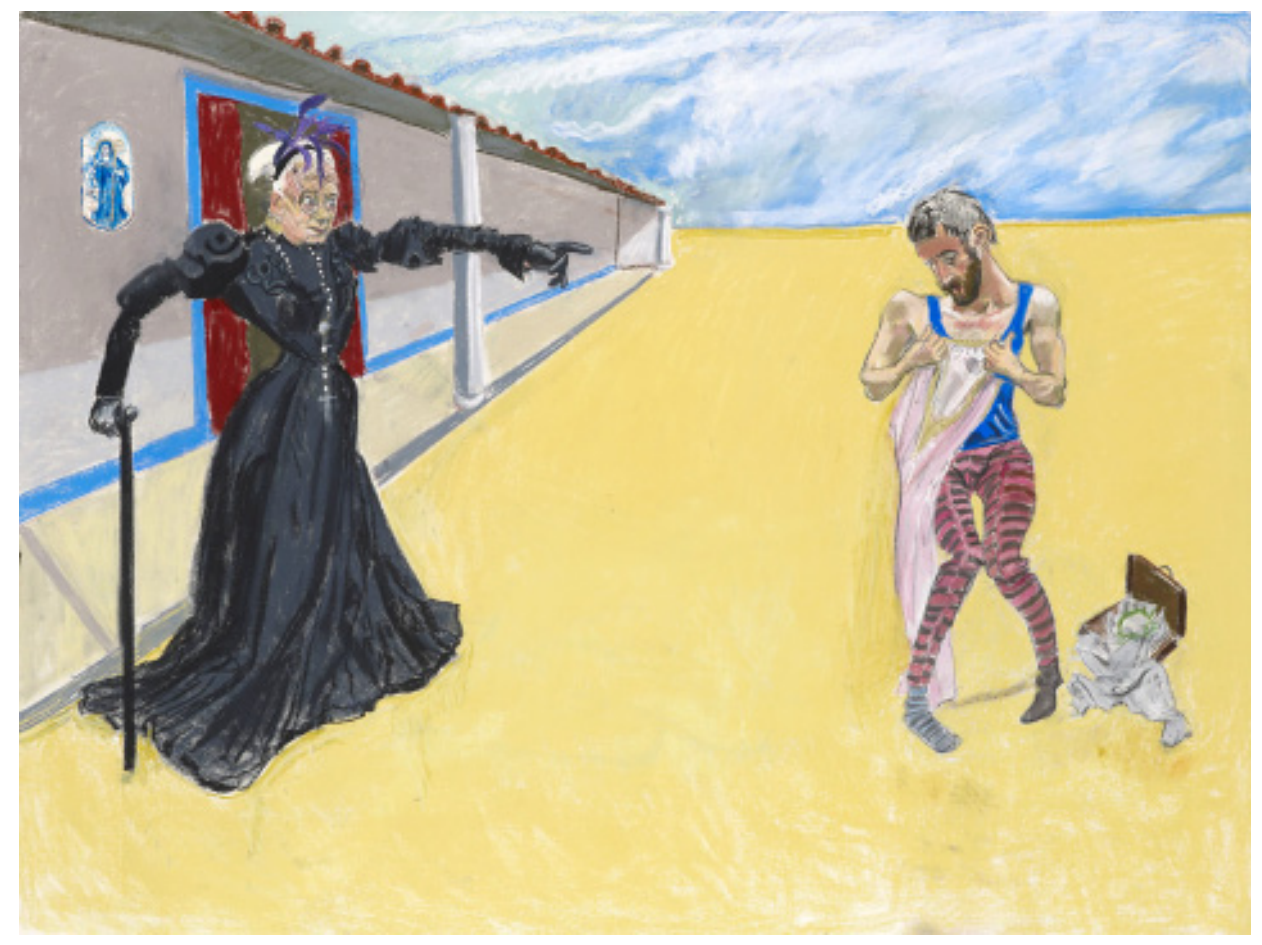

Três deles reportam-se ao trecho romanesco que se desenvolve a Oriente: Mary faz luvas, Sonho, A Terra Santa.

Reterei a minha atenção nestes três quadros, não sem antes lembrar que o Oriente será, na obra de Eça de Queirós, uma permanente referência mítica e real. A rápida viagem por ele empreendida ao Egipto, Palestina, Síria e Líbano, nos finais de 1869, com o pretexto de assistir à inauguração do Canal de Suez, irá marcá-lo indelevelmente, a qual, a par das suas passadas e futuras leituras orientalistas, confirmará e acentuará o seu interesse pelo Oriente e facultar-lhe-á outras viagens fabulosas, do Próximo ao Extremo-Oriente, seus contemporâneos e antigos.

Um sopro oriental perpassará do princípio ao fim sua obra, alimentando-lhe a imaginação, fornecendo-lhe cenários, temas, imagens, quer de um modo explícito e fundamental em obras de índole tão diversa quanto O Egipto - notas de viagem, coligidas e publicadas postumamente (1926), ou os contos A morte de Jesus (1870) e Santo Onofre (1893), a novela O mandarim (1880) e sobretudo o romance $A$ relíquia (1887), e ainda, de modo mais pontual mas significativo, A correspondência de Fradique Mendes ou O mistério da estrada de Sintra, para além de textos de carácter jornalístico mais tarde recolhidos em Notas contemporâneas e em Cartas de Inglaterra.

É pois legítimo falar de imaginário oriental na sua obra e não será desadequado fazer suas as palavras que pôs exatamente na boca de Teodorico: "Esta jornada à terra do Egipto e à Palestina permanecerá sempre como a glória superior da minha carreira" (QUEIROZ, 1999, p. 5).

Eça participará, pois, no movimento de apropriação imaginária que, ao longo dos séculos, o Ocidente foi fazendo do Oriente, daquela invenção do Oriente que Edgard Quinet, em meados do século XIX, designara por 
Renascença oriental; tratou-se, como é sabido, de um Oriente "orientalizado" pelo Ocidente, na formulação célebre de Edward Said (1990, p. 77).

Sabemos que o Oriente sempre foi visto pelo Ocidente como algo mais para além daquilo que era empiricamente conhecido a seu respeito, criando-se em torno dele uma mitologia. O Oriente surge como um perigo insinuante; de lá vem o cristianismo, mas também temíveis conquistadores e, sobretudo, o islão, o que faz com que, a partir da Idade Média, o Oriente adquira uma série de representações que se vão perpetuar no imaginário ocidental; dele emana a traição, a devassidão, a lascívia, a heresia... Por esse "palco teatral anexo à Europa" (SAID, 1990, p. 73), passará um repertório riquíssimo do ponto de vista cultural: a Esfinge, Cleópatra, o Éden, Sodoma e Gomorra, Osíris e Íris, a Babilónia, Prestes João e muitos outros; cenários, nomes reais ou imaginários, monstros, heróis, prazeres, desejos, terrores que alimentarão durante séculos a imaginação europeia.

Este Oriente inventado será reescrito segundo a fantasia de cada um e rapidamente se torna, nas palavras de Philippe Desan, "un immense fantasme: le fantasme de l'Occident qui cherche des origines dans un monde moins rigide." (1983, p. 16) Por isso o Oriente aparece também como feminino, seminal, sensual, misterioso, primitivo. No fundo ele é o Outro, tudo o que está ausente e se deseja, uma espécie de pátria subjetiva onde cada um encontra o que procura.

Ora Teodorico partirá para Oriente nessa atitude de busca - busca de uma relíquia para a Titi e busca de si mesmo, dessa pátria subjetiva, por mais ou menos consciente que estivesse dessa busca. Será, pois, com uma visão estereotipada do Oriente que dele se aproxima, e quer Eça, quer Paula Rego mostrar-se-ão atentos ao seu preconceito orientalista, designadamente à típica confusão do Oriente com pansexualismo: fecundidade, promessa, ameaça sexual, sensualidade, desejo - tudo isso o Oriente sugere ao viajante ocidental do século XIX, que tende, no dizer de Lisa Lowe, a fazer a "projection of the oriental Other as female" (1986, p. 32). Ora quer Paula Rego, quer Eça de Queirós lançarão, sobre esse preconceito, o seu sarcasmo.

Relembre-se o delicioso passo d' A relíquia em que Teodorico, tremendo de emoção e entusiasmo pela sensualidade misteriosa da mulher oriental, penetra nos "segredos deslumbradores dum serralho":

Então, uma portinha branca, sumida no muro caiado, rangeu a um canto, de leve: e uma figura entrou, velada, vaga, vaporosa. Amplos calções turcos de seda carmesim tufavam com languidez, desde a sua cintura ondeante, até aos tornozelos, onde franziam, fixos por uma liga de ouro; os seus pezinhos mal pousavam, alvos e alados, nos chinelos de marroquim amarelo; e através do véu de gaze que lhe enrodilhava a cabeça, o peito e os braços - brilhavam recamos de ouro, centelhas de jóias e as duas estrelas negras dos seus olhos. Espreguicei-me, túmido de desejo. (QUEIROZ, 1999, p. 102-103). 
Mas com que se depara ele quando a realidade lhe é desvelada?

Por trás dela Fatmé, com a ponta dos dedos, ergueu-lhe o véu devagar, devagar - e de entre a nuvem de gaze surgiu um carão cor de gesso, escaveirado e narigudo, com um olho vesgo, e dentes podres que negrejavam no langor néscio do sorriso. [...] A circassiana, requebrando-se, com o seu sorriso pútrido, veio estender-nos a mão suja, a pedir "presentinhos" num tom rouco de aguardente. Repeli-a com nojo. Ela coçou um braço, depois a ilharga; apanhou tranquilamente o seu véu, e saiu arrastando as chinelas. (QUEIROZ, 1999, p. 103).

Atentemos agora mais detidamente n'A relíquia de Paula Rego. Lembre-se, porém, antes, que Paula Rego pontualmente ilustra o romance, mas sobretudo serve-se dele para ler o mundo. Ela própria admite, no catálogo da série inspirada em $O$ crime do Padre Amaro: "O romance é só um ponto de partida, um detonador; depois as imagens invadem tudo, como uma caixa de surpresas, como bonecas russas" (REGO, 1999, s/ paginação). Também na presente série o romance é um detonador para ler dois assuntos que se entrelaçam no universo de Paula Rego: as relações de poder, designadamente o poder dominador das mulheres, e a nomeação do inominável, do impensável, do interdito que invade as relações humanas.

A pintura de Paula Rego exibe um forte desejo de narratividade que, de um modo recorrente, passa pela encenação de versões alternativas às histórias canónicas, as quais, mantendo vivas as contradições, veiculam a subversão da ordem, dos poderes. Diz a pintora a este respeito: "Os meus temas favoritos são os ‘jogos’ provocados pelo poder, o domínio e as hierarquias. Dá-me sempre vontade de pôr tudo de pernas para o ar, desalojar a ordem estabelecida." (apud POMAR, 1996, p. 19)3³ Não é, porém, um universo caótico ou labiríntico o de Paula Rego, como muito bem perceciona Agustina Bessa-Luís quando nota que,

Começando a olhar para Paula Rego, as ideias vão aparecendo, vão-se cruzando mas sem darem lugar ao labirinto. É uma pintura, não tanto produzida nas ruínas da infância, mas toda ela uma ruína renegada. Ela constrói, rompe todos os laços, faz combinações novas de ideias" (BESSA-LUÍS, s.d., p. 106).

São histórias, as dos seus quadros, onde a violência eclode pela cor e pela forma, transportando o poder da desordem; essa é, porventura, a primeira razão pela qual a violência tanto importa ao universo de Paula Rego, dando largas à expressão do universo subliminal, a um mundo povoado de fantasmas, comandado pelas forças do inconsciente e fazendo-o emergir a par do mundo da vigília ou em osmoses por vezes delirantes com ele, com os seus valores, obsessões, terrores. A pintora recorre com gosto ao humor negro para lhe dar expressão, ensaiando também por essa via pontes de diálogo com o texto irónico queirosiano, nomeadamente exerci- 
tando a paródia irreverente. À ironia dúplice e por vezes amarga mas, em última análise, reformista e solar de Eça de Queirós, responde Paula Rego com um humor negro, feroz, provocador, estranho e desconcertante no seu furor de matriz anárquica e iconoclasta.

Como disse, deterei a minha atenção nos três quadros de Paula Rego que se centram na quête oriental de Teodorico, o Raposão. O segundo capitulo do romance abre com a seguinte frase: "Foi num domingo e dia de S. Jerónimo que meus pés latinos pisaram, enfim, no cais de Alexandria, a terra do Oriente, sensual e religiosa." (QUEIROZ, 1999, p. 68). Ela importa especialmente na medida em que diz as duas linhas motivadoras dos passos de Teodorico na tal quête a Oriente: "ir rezar, e ir amar" (QUEIROZ, 1999, p. 72) - palavras também suas, como sua é aquela célebre exclamação, proferida à chegada a Jerusalém: "cá está o belo Raposo em Jerusalém!" (QUEIROZ, 1999, p. 90).

Os quadros são, como referi: Mary faz luvas, Sonho e A Terra Santa.

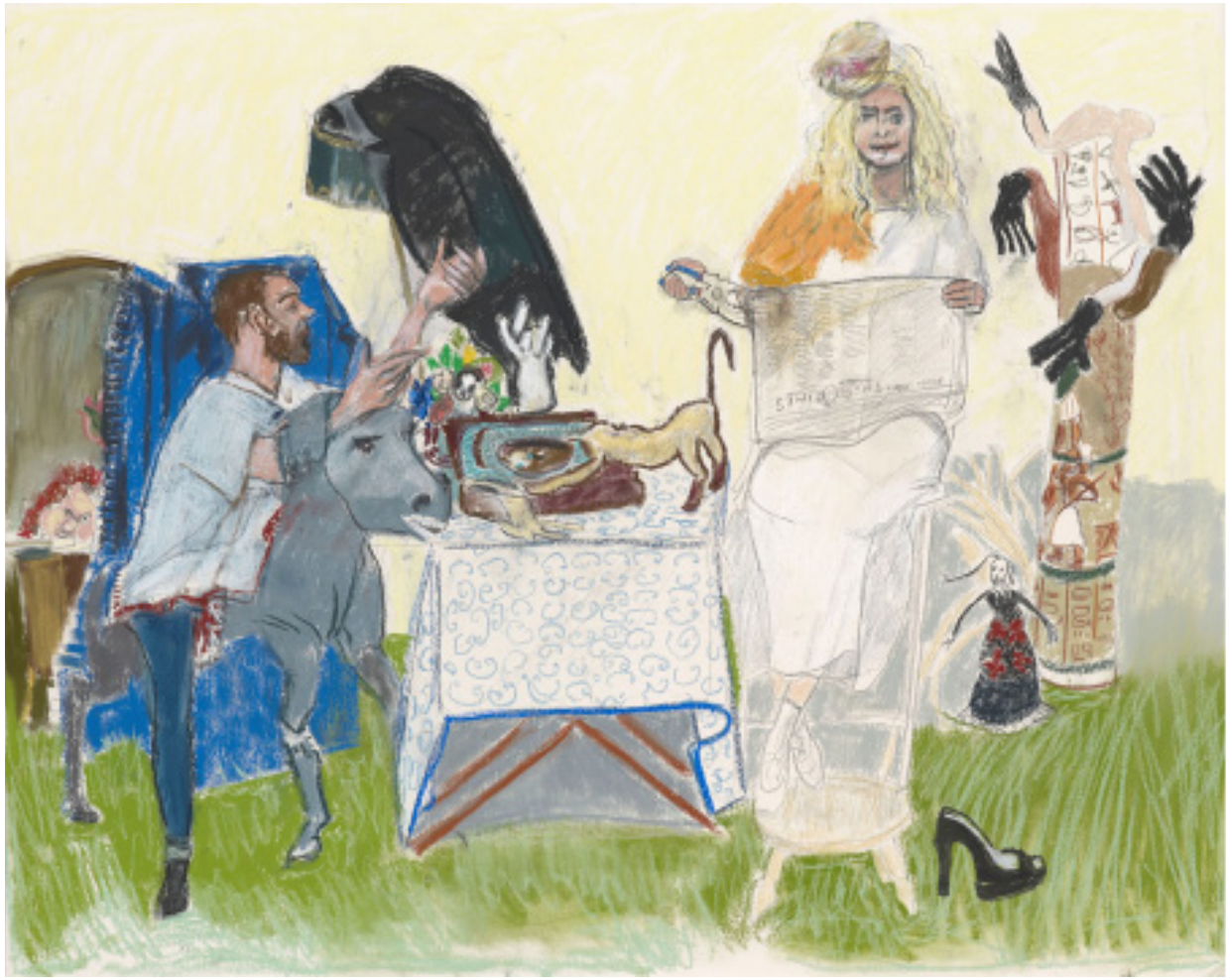

Mary faz luvas dá a ver as relações de subjugação erótica de Teodorico perante a luveira Mary durante a breve estadia daquele em Alexandria, à chegada ao Oriente. O quadro aproxima-se de uma cena específica do romance, mas não como ilustração que persiga a exatidão; faz, isso sim, uma interpretação das relações de Teodorico e Mary, conjugando elementos que o romance vai fornecendo nas breves páginas que dedica às relações entre eles. Essas relações assentarão num equívoco, visto que Teodorico não se mostra capaz de identificar o seu carácter meramente comercial, digamos assim, e por isso sofrerá o desaire de se ver trocado por um italiano, mal deixa Mary por uns dias para prosseguir a sua viagem a Jerusalém. 
A nota orientalista do quadro é dada por Paula Rego através da coluna do anúncio da luveira, uma coluna com motivos egípcios, digamos, que se afasta da descrição queirosiana, a qual diz a respeito tão só o seguinte: "pendurada sobre a porta de uma lojinha discreta, uma pesada mão de pau, tosca e roxa - e por cima, em tabuleta negra, estes dizeres convidativos a ouro: 'Miss Mary, Luvas e Flores de Cera”'( QUEIROZ, 1999, p. 73). Voltarei aqui.

O quadro contempla mais alguns elementos que aparecem na descrição queirosiana, nomeadamente o gato, o Times lido por Mary, o vaso de rosas e magnólias pousado no balcão e, claro, a própria figura física de Mary. Esta, a quem ele dará o petit nom de Maricoquinhas (QUEIROZ, 1999, p. 74) e a quem mimoseia com as designações amorosas de "rechonchudinha" e de "riquiquitinha" (QUEIROZ, 1999, p. 77), aparece desde o primeiro momento aos olhos de Teodorico, para quem sacro e profano se confundem, como uma espécie de anjo erotizado:

O que me prendeu logo foram os seus olhos azul-claros, de um azul que só há nas porcelanas, simples, celestes, como eu nunca vira na morena Lisboa. Mas encanto maior ainda tinham os seus cabelos, crespos, frisadinhos como uma carapinha de ouro, tão doces e finos que apetecia ficar eternamente, devotamente, a mexer-lhe com os dedos trémulos; e era irresistível o profano limbo luminoso que eles punham em torno da sua face gordinha, de uma brancura de leite onde se desfez carmesim, toda tenra e suculenta. (QUEIROZ, 1999, p. 73-74)

Ora Paula Rego apresenta Mary, exatamente como um ser ascensional, livre de sapatos que a prendam à terra, colocada numa espécie de peanha que a deixa em posição de superioridade em relação a Teodorico, para o qual de resto não olha. Mary está numa atitude de domínio, ladeada à direita e à esquerda por mascotes - o gato branco que ela tem ao colo na cena queirosiana, indiciando o caráter traiçoeiramente felino que ela revelará, e aqueloutro ser híbrido, um simulacro de uma boneca com cabeça de cão ou de caveira, nascido apenas do pincel de Paula Rego, e que sinaliza uma ameaça, um alarme.

Mas o alarme está contemplado no texto de Eça através de uma subtileza irónica, quando o narrador diz com a ingenuidade de quem não atende aos sinais: "Ela era silenciosa: mas o seu simples sorrir com os braços cruzados, ou o seu modo gentil de dobrar o Times, saturava o meu coração de luminosa alegria." (QUEIROZ, 1999, p. 74). Esse modo gentil, dá-o Paula Rego através de um ameaçador alicate dentado com o qual Mary pinça o Times. Aquela é uma arma de dominação de Mary, com a qual manipula o Times e o próprio Teodorico obviamente. Aliás ela é mestra na manipulação, ela manipula luvas, metonímia de mãos, instrumentos de domínio, de poder. Teodorico está nas mãos de Mary. 
Retome-se a coluna com motivos egípcios, acima referida. Ela é anúncio da luveira de Paula Rego. Tem quatro braços, com quatro mãos negras ameaçadoras e possui ela própria uma dimensão antropomórfica, sugerindo um movimento corporal e uma cabeça feminina. Não se esqueça que Topsius chamava a Mary "a nossa simbólica Cleópatra" (QUEIROZ, 1999, p. 74). Ela simboliza poder erótico que exerce sem apelo sobre Teodorico: "'seu portuguesinho valente, seu bibichinho"' (QUEIROZ, 1999, p. 74), como ela lhe chama.

Teodorico ocupa em posição espacialmente inferior o lado esquerdo do quadro. Separa-os ou aproxima-os aquele balcão comercial no meio do qual Paula Rego desenha um objeto que parece ser uma roleta, dando a chave da natureza lúdica, de jogo de azar, daquela relação. Quem controla a roleta é Mary - uma luva sua e a sua gata marcam o terreno.

A representação de Teodorico no trabalho de Paula Rego não encontra nenhuma correspondência na cena romanesca, na qual não há referência a nenhum cavalo, nem a qualquer figura aproximável da silhueta do corvo gigante que domina o nosso herói. Há sim, na descrição dos comportamentos de Teodorico, uma certa animalidade, ele assume traços que o aproximam do reino animal. Ele é, aliás, o "bibichinho" de Mary. Ao longo do romance, termos como bandulho, rafeiro, touro, rês, cão surgem referidos a Teodorico, e verbos como morder, rosnar, refocilar, ruminar têm por sujeito o mesmo Teodorico, conhecido por o Raposão, recorde-se. Ora talvez caminhe por aí a interpretação de Paula Rego ao dar-nos um Teodorico algo híbrido numa espécie de con-fusão com o cavalo. A quarta pata do cavalo está em simbiose com a perna de Teodorico e o seu pé assemelha-se a um dos cascos.

Teodorico é um pobre bicho homem nas mãos manipuladoras da angélica Mary, sob a sombra fantasmática de um corvo ameaçador que designará simbolicamente a igualmente manipuladora e vigilante Titi. Teodorico, incauto, entrega-se em oferenda, de mãos abertas nas mãos das mulheres. E será vitimado como nos é indiciado pela alusão ameaçadora à morte, à decapitação, constituída pela cabeça sexualmente indefinida que surge numa espécie de cepo patibular no canto inferior esquerdo do quadro.

Este é um frequente destino dos homens no universo de Paula Rego: serem presas fáceis das mulheres, seres poderosos, cruéis, dominadores, independentemente de corporizarem a luz ou a sombra, de serem anjos ou demónios, de serem Marys ou Titis.

A relíquia é provavelmente de todos os romances queirosianos aquele que mais importância dá aos sonhos, basta lembrar que o romance se organiza num tríptico que tem como painel central o tal sonho no qual Teodorico regressa à Antiguidade cristã, assiste à pregação, julgamento e crucificação de Jesus e reescreve a história sagrada, negando a ressurreição. Porém, cada um dos dípticos contempla por seu turno um sonho. O primeiro, sonhado a Oriente, durante a viagem marítima que leva Teodorico de Alexandria para Jafa na Palestina, merece a atenção da pintora. 
É bem natural que o sonho, com os seus mecanismos de deslocação e condensação, a sua natureza densamente visual e sua tendência para a narratividade, suscite o interessa de uma pintora como Paula Rego.

O quadro em causa designa-se Sonho e segue de perto o episódio do romance que ocupa três breves páginas.

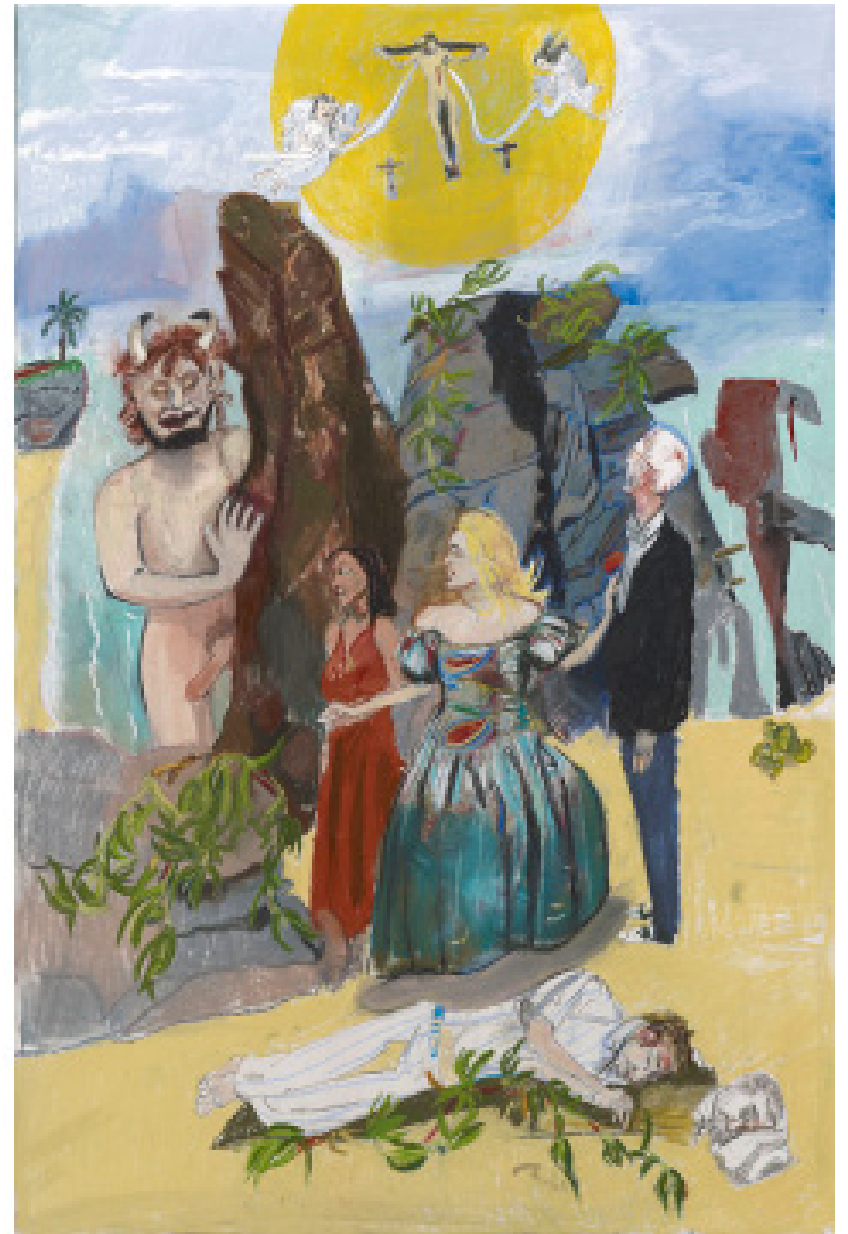

O primeiro plano do quadro alude exatamente ao disparo do sonho e à criação de um duplo onírico de Teodorico que, note-se, adquire desde logo uma aura demoníaca, orelha e testa vermelhas e uma espécie de chifre nascente e ganha vestes brancas, cor que no romance transmite frequentemente uma forte carga erótica. Num segundo plano, visualiza-se o início do sonho nos termos descritos por Eça de Queirós:

Mas uma tarde, ao escurecer, tendo cerrado os olhos, pareceu-me sentir sob as chinelas um chão firme, chão de rocha, onde cheirava a rosmaninho: e achei-me incompreensivelmente a subir uma colina agreste de companhia com Adélia e a minha loura Mary - que saíra de dentro do embrulho, [...] Depois, por trás de um penedo, surgiu-nos um homem $\mathrm{nu}$, colossal, tisnado, de cornos; os seus olhos reluziam, vermelhos como vidros redondos de lanternas [...]. Eu percebi bem que era o Diabo; mas não senti escrúpulo, nem terror. A insaciável Adélia atirava olhadelas oblíquas à potência dos seus músculos. Eu dizia-lhe, indignado: "Porca, até te serve o Diabo?" (QUEIROZ, 1999, p. 82) 
Eis o Oriente, a Terra Santa, como território do Diabo, como espaço da lubricidade, da sexualidade sem freio, da animalidade - isto é, correspondendo aos tópicos do orientalismo oitocentista. Paula Rego acentua com ironia o lugar-comum orientalista sugerindo um pansexualismo dito pela ereção do diabo, exorbitada esta por aquele fantasma fálico em que o próprio Diabo se apoia. E estabelece-se entre os três protagonistas ocidentais, através dos braços brancos de Mary, uma espécie de corrente de cumplicidade desviante, de atração pelo excesso que o monstro diabólico corporiza.

Paula Rego tem povoado nos últimos anos a sua pintura de figuras monstruosas, criaturas fora do conforme, que adotam comportamentos antissociais ou que dão corpo ao que a sociedade tende a não querer ver: Disso são exemplo quadros de distintas séries, como:

\section{Mulher cão}

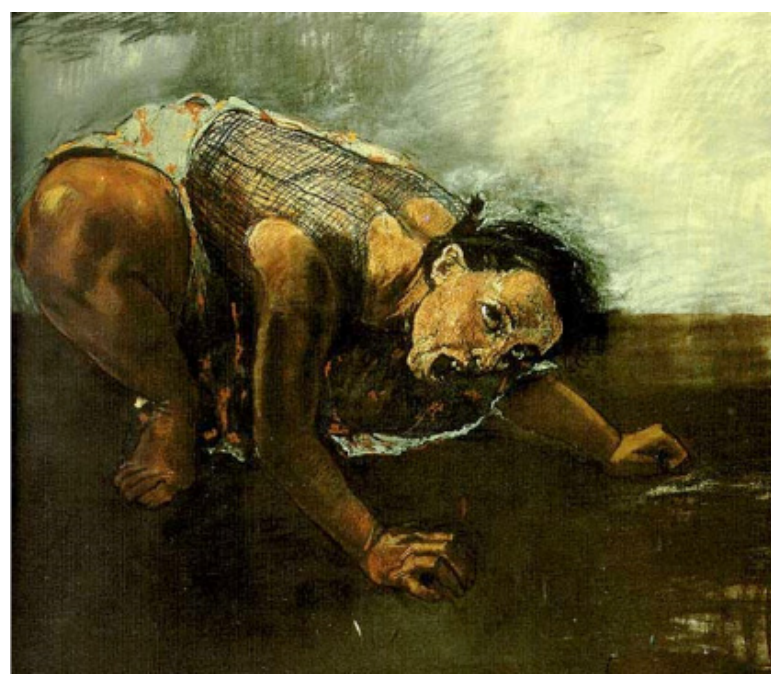

O homem almofada

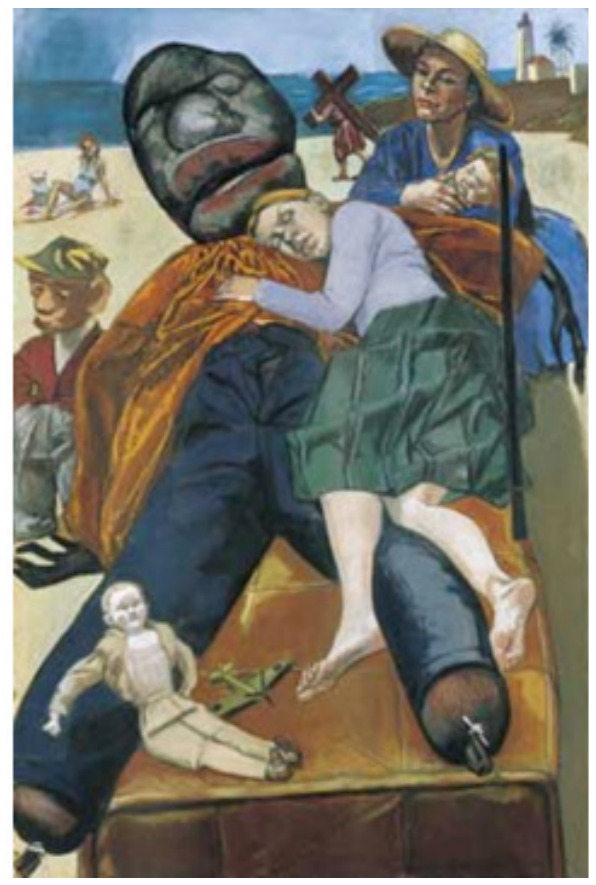




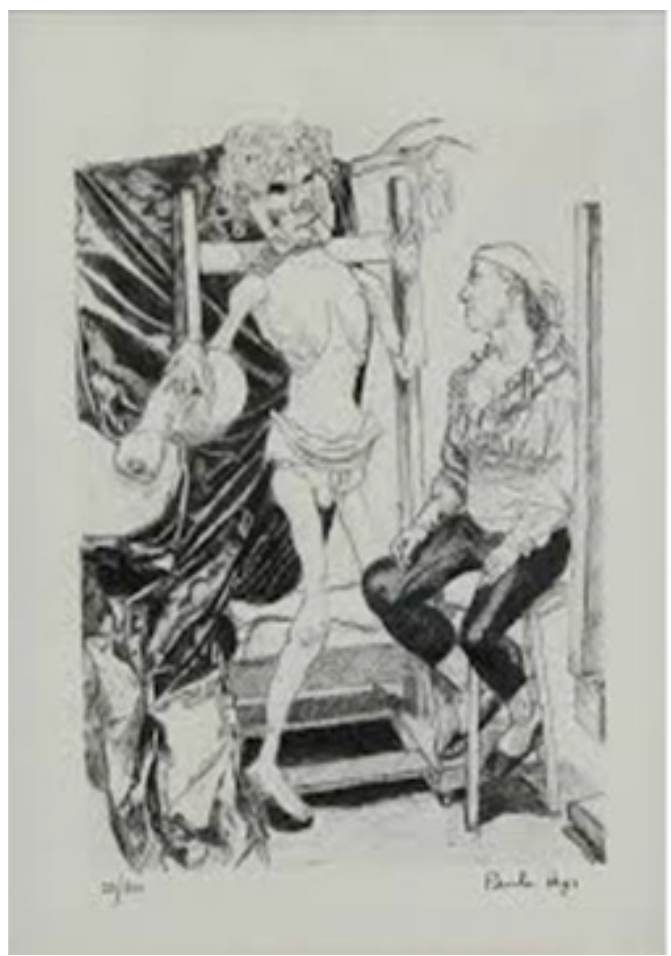

Há nela uma atração pelo excesso que é conjugável com o traço expressionista da sua pintura e que a coloca no limiar, providenciando um espaço onde é possível pensar o impensável. No caso de Sonho, será um espaço onde é possível experimentar a iconoclastia, porque o que o quadro narra num plano de fundo e a um nível etéreo é a ascensão de Cristo. Diz o texto queirosiano:

Defronte de nós, muito longe, o céu desdobrava-se como um vasto estofo amarelo: e sobre esse fundo vivo, cor de gema de ovo, destacava um negríssimo outeiro, tendo cravadas no alto três cruzinhas em linha, finas e de um só traço. O Diabo, depois de escarrar, murmurou, travando-me da manga: "A do meio é a de Jesus, filho de José, a quem também chamam o Cristo; e chegámos a tempo para saborear a Ascensão." (QUEIROZ, 1999, p. 82).

Temos portanto o Diabo como figura dominante do quadro, tal como no romance, retirando dimensão sacra à cena da Ascensão, relegada para um diminuto último plano (o amarelo sacro torna-se de gema de ovo e a Ascensão torna-se coisa saboreável), e abrindo as portas à iconoclastia que por ele será verbalizada perante Teodorico. Embora este, no quadro, ainda lance um olhar para a cena da Ascensão, vai sendo catequizado pelo Diabo, o qual faz a apologia dos deuses pagãos que, diz ele, "se misturavam à vida humana, divinizando-a" (QUEIROZ, 1999, p. 83) e que "Por isso eram amados com um amor que não mais voltará” (QUEIROZ, 1999, p. 83), e "Uma alegria heroica, subindo para o Sol, fazia os homens iguais aos deuses." (QUEIROZ, 1999, p. 84).

Mas aparecera este carpinteiro de Galileia - e logo tudo acabara! [continua o Diabo] A face humana tornara-se para sempre pálida, cheia de mortificação: uma cruz escura, es- 
magando a terra, secava o esplendor das rosas, tirava o sabor aos beijos - e era grata ao deus novo a fealdade das formas. (QUEIROZ, 1999, p. 84)

No romance, Teodorico, afinal como parece acontecer no quadro com as suas companheiras, adere aos pontos de vista iconoclastas do Diabo, a ponto de o consolar, dizendo-lhe: “Deixe estar, ainda há-de haver no mundo muito orgulho, muita prostituição, muito sangue, muito furor! Não lamente as fogueiras de Moloch. Há-de ter fogueiras de judeus."' (QUEIROZ, 1999, p. 84). Assiste-se, aqui, a um primeiro passo de Teodorico no exercício revisionista do Cristianismo que fará, e, talvez por isso, a figura de um sapo - com a carga simbólica da metamorfose que ele transporta - é colocada por Paula Rego no canto inferior direito do quadro, exatamente por detrás de Teodorico. O contacto com a Terra Santa transformará Teodorico e o seu olhar sobre o Cristianismo - este é porventura o primeiro passo. Talvez por isso a última imagem onírica que o assalta seja a Titi, "lívida, terrível”, pronta a espancá-lo com o seu livro de missa e berrando: “Olha o Teodorico com o porco-sujo!”' (QUEIROZ, 1999, p. 85). Paula Rego também a sugere ameaçadora em termos fantasmáticos. Não a podemos reconhecer naquele perfil negro e seco que parece fissurar o outeiro cinzento ou na perturbante figura híbrida e monstruosa do extremo direito do quadro?

A Terra Santa é certamente o mais complexo quadro da série e, de todos, o que melhor faz o referido jogo duplo de ilustrar e interpretar, não seguindo, porém, nenhuma cena específica do romance, mas incorporando vários momentos e diversos espaços da narrativa, como se fosse um trailer de um filme.

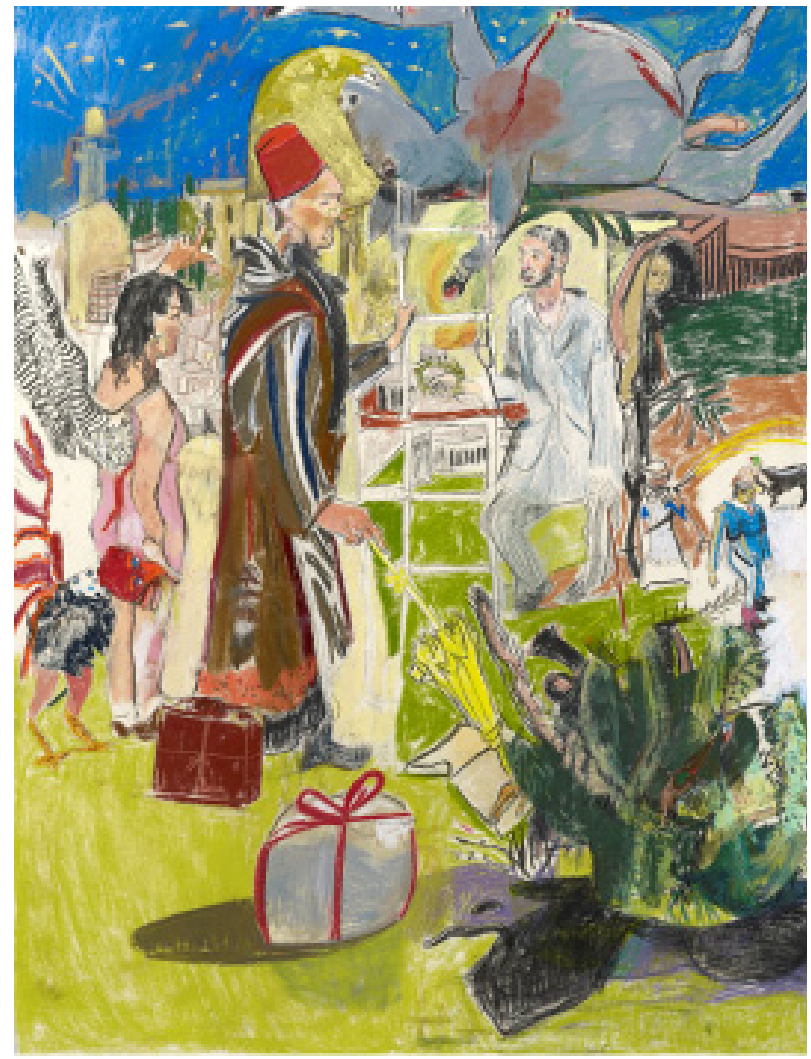


O quadro organiza-se espacialmente a partir daquele escadote central que parece estruturar a encenação e que entendo como uma metáfora criada pela pintora da quête levada a cabo por Teodorico a Oriente. O escadote é sustentado por Topsius, porque é ele o erudito companheiro do protagonista que o vai guiando pela geografia arqueológica e pela história cristã da Terra Santa. É ele que mostra e explica a Teodorico o mundo oriental. Talvez por isso Paula Rego opte por no-lo apresentar vestido ao modo oriental, em termos nunca referidos pelo romance; ele é o Oriente para Teodorico; é através dos seus olhos de orientalista europeu que Teodorico verá o Oriente - olhos armados de uns "óculos sôfregos" (QUEIROZ, 1999, p. 117), porque perscrutadores, "óculos de ouro na ponta do bico” (QUEIROZ, 1999, p. 70), também no pincel de Paula Rego. O amarelo de ouro estende-se ao guarda-sol de Topsius, que no romance é verde e vasto. Paula Rego vê-o como um instrumento de procedimento analítico, uma espécie de apontador com o qual o historiador mostra; talvez por isso ganhe a cor dos óculos.

No centro superior e inferior do quadro, em lugares de destaque, dois elementos que remetem para um outro lado da referida quête oriental de Teodorico: o sexo. Quando chegara a Alexandria, Teodorico logo declarara que "desejava sem tardança ir rezar, e ir amar "(QUEIROZ, 1999, p. 72). Ora aqueles dois elementos indiciam a quête sexual: o embrulho da camisinha de Mary, embaixo, cuja presença pontua a narrativa romanesca, e o burro, em cima, em posição exibicionista de abandono sexual, o qual nunca é explicitado nestes termos no romance, mas que Paula Rego, logo no quadro Mary faz luvas associara hibridamente a Teodorico. O Oriente mais uma vez afirmado como território pansexual.

Aliás, a figura à esquerda, colocada por detrás de Topsius, é uma mulher anjo, sinédoque de todas as mulheres entrevistas e desejadas a Oriente, e que parece ser uma espécie de Mary na forma de anjo, com o cabelo de Adélia, apontando, mostrando, explicando, como um anjo mensageiro, o caminho de um outro Oriente, diferente do apontado por Topsius - o Oriente da sensualidade animalesca que o burro, para o qual parece apontar, atesta. Repare-se que a mulher anjo está por seu turno dominada e presa à terra por uma assustadora ave de rapina com cauda de fogo e pernas humanas. Mulher anjo e ave de rapina constituem uma erupção do domínio onírico, da inteira responsabilidade de Paula Rego, mas que o romance com sua forte componente onírica consente. Recorde-se que a descrição de três sonhos entrecortam a narrativa de viagem de Teodorico.

Mas, no centro absoluto do quadro, vislumbra-se a coroa de espinhos, pouco visível, num segundo plano, exibida por um Teodorico alquebrado, com dificuldade em sustentar uma posição ereta, em nada impante, absolutamente contrário ao Teodorico machista que no início do romance, de partida para Jerusalém, se pretende comparável a um touro: ao sair de Alexandria anunciara a Mary que voltaria como um touro (QUEIROZ, 1999, p. 76). Aliás, Paula Rego opta por uma piscadela de olho sarcástica ao fazer uma alusão a uma faena numa praça de touros no lado direito do quadro. 
Digamos que aquele Teodorico que perseguiu a relíquia para a Titi, que é afinal apenas um "soberbo galho", "arranjadinho em coroa" (QUEIROZ, 1999, p. 120), assinalado aliás, à direita, no quadro, é um Teodorico "farto" do Oriente, um Teodorico que se negaria, a partir de um certo momento, a continuar a viagem arqueológica com Topsius [note-se as múltiplas alusões no quadro à arquitetura antiga], gritando-lhe: “- Estou farto!... Irra! E aqui lho declaro, Topsius, solenemente: de hoje em diante não torno a ver nem mais um pedregulho, nem mais um sítio de religião... Irra! Tenho a minha dose: e forte, muito forte, doutor!" (QUEIROZ, 1999, p. 218). É o mesmo Teodorico que, ao saber que vai deixar o Oriente, gritará: "atirando patadas ao ladrilho. - Ainda bem, que estava farto do Oriente!... Irra! Que não apanhei aqui senão soalheiras, traições, sonhos medonhos e botas pelos quadris! Estava farto!" (QUEIROZ, 1999, p. 228)

Este é um Teodorico rechaçado pelo Oriente, que corporiza o lado não heroico da jornada. Um trecho do romance alusivo à viagem de regresso, do troço Jerusalém-Alexandria, parece difusamente ilustrado pelo quadro. Teodorico reencontrara no barco uma religiosa na qual já se fixara lubricamente à ida (QUEIROZ, 1999, p. 86-7) e que de certo modo até já conspurcara com o embrulho da camisinha de Mary:

\begin{abstract}
Afastava-me devagar da amurada, quando roçou por mim a longa capa de lustrina de uma religiosa [repare-se na alusão feita no quadro]; e de entre a sombra pudica do capuz, que se voltou de leve, um fulgor de olhos negros procurou as minhas barbas potentes. Que maravilha! Era a mesma santa irmã que levara nos seus castos joelhos, através destas águas da Escritura, a camisa imunda da Mary! (QUEIROZ, 1999, p. 229)
\end{abstract}

Teodorico começa a imaginar "um amor de monja mais forte que o medo de Deus, de um seio magoado pela estamenha de penitência caindo, a tremer e vencido, entre os meus braços valentes!...” (QUEIROZ, 1999, p. 230). Prepara-se para prodigalizar os seus avanços, mas "uma vaga enjoadora” (QUEIROZ, 1999, p. 230), como diz o autor, obriga-o a entregar-se ao humilhante vómito e a retirar-se para o camarote. Desperta ao atracar no cais de Alexandria, e o texto romanesco relata o seguinte, que o quadro pontualmente ilustra:

E outra vez, estremunhado e esguedelhado, te avistei, terra baixa do Egipto, quente e da cor de um leão! Em torno aos finos minaretes voavam a sombras serenas. O lânguido palácio dormia à beira da água entre palmeiras. Topsius sobraçava a minha chapeleira, serrazinando coisas doutíssimas sobre o antigo farol. E a pálida religiosa já deixara o "Caimão", pomba do ermo escapada ao milhafre - porque o milhafre no seu voo fechara a asa, sórdidamente enjoado! (QUEIROZ, 1999, p. 230)

Ora, em primeiro plano, do lado direito do quadro, Paula Rego dá-nos a ver uma feminil e frágil ave, não branca mas verde, sobrepondo-se a uma ave maior de bico adunco e masculinas cores negras e cinzas. Não metaforizará a cena a pomba e o milhafre, ambos ladeados por uma natureza adversa dada pelo agressivo e imponente cato $^{4}$ verde? Mas quem 
está em atitude de dominação, como é comum no universo da pintora, é a feminil pomba.

Eis o Teodorico de Paula Rego na Terra Santa, afinal bastante próximo do Teodorico, Raposão sempre batido, de Eça de Queirós.

Concluindo, Eça de Queirós e Paula Rego, em suportes distintos, recorrendo a soluções estéticas à primeira vista diametralmente opostas, a mais de um século de distância um do outro, apropriaram-se do lugar comum orientalista oitocentista para exercerem a sua iconoclastia e para lançarem o seu olhar subversor sobre os respetivos mundos.

\section{REFERÊNCIAS BIBLIOGRÁFICAS}

BESSA-LUÍS, Agustina; REGO, Paula. As meninas. Lisboa: Três Sinais Editores, s.d.

DESAN, Philippe. L'Autorité Orientaliste de Flaubert. Nottingham French studies, XXI, 1 May, 1983.

LOWE, Lisa. The Orient as Woman in Flaubert's Salammbô and Voyage en Orient. Comparative Literature Studies. XXIII, Summer, 1986.

McEWEN, John. Paula Rego. London: Phaidon, 1997.

POMAR, Alexandre. Pinturas de histórias. Tabacaria, $\mathrm{n}^{\circ}$ 2, inverno 1996.

QUEIROZ, Eça de. A relíquia. Lisboa: Livros do Brasil, 1999.

REGO, Paula. O crime do Padre Amaro, Catálogo da exposição do CAM da Fundação Calouste Gulbenkian, 1999.

SAID, Edward W. Orientalismo - O Oriente como invenção do Ocidente. São Paulo: Companhia das Letras, 1990.

Recebido para publicação em 17/09/2015

Aprovado em 29/01/2016

\section{NOTAS}

* Professora Emérita da Universidade do Porto. O presente artigo foi desenvolvido no âmbito do Programa Estratégico Literatura e Fronteiras de Conhecimento - Políticas de Inclusão do Instituto de Literatura Comparada Margarida Losa (UID/ELT/00500/2013 | POCI-01-0145-FEDER-007339).

2As reproduções que se seguem foram retiradas do site http://www.marlboroughlondon. com/exhibitions/paula-rego-the-last-king-of-portugal-and-other-stories/, de https:// www.google.com.br/search?q=imagens+rel\%C3\%ADqui+paula+rego\&rlz=1C1EODA_ enBR524BR615\&espv $=2 \& b i w=1242 \& b i h=585 \&$ tbm $=i s c h \& t b o=u \& s o u r c e=u n i v \& s a=X \&$ ved=0ahUKEwiYtM-kk7rMAhVKIJAKHbCkAdsQsAQIHg e de https://www.publico.pt/ culturaipsilon/noticia/nova-exposicao-de-paula-rego-em-londres-inspirada-por-eca-de-queiros-1671206.

3 Num outro momento declara em termos próximos: "I always want to turn things on their heads, to upset the established order, to change heroines and idiots. If the story is "given" I take liberties with it, to make it conform to my own experiences, and to be outrageous. At the sametime as loving the stories I want to undermine them, like wanting to harm the person you love." (apud MCEWEN, 1997, p.138.)

$4 \mathrm{Na}$ ortografia brasileira, "cacto". 